\title{
BIOPIRATARIA E CONHECIMENTOS \\ TRADICIONAIS: AS FACES DO BIOCOLONIALISMO E SUA REGULAÇÃO
}

Magno Federici Gomes

Pós-doutor em Direito Público e Educação pela Nova Universidade de Lisboa, Portugal. Pósdoutor em Direito Civil e Processual Civil. Doutor em Direito e Mestre em Direito Processua pela Universidad de Deusto, Espanha. Professor do Programa de Mestrado em Direito Ambiental e Desenvolvimento Sustentável pela Escola Superior Dom Helder Câmara. E-mail: magnofederici1@yahoo.com.br

José Adércio Leite Sampaio

Doutor e Mestre em Direito pela Universidade Federal de Minas Gerais. Professor da PUC Minas e da Escola Superior Dom Helder Câmara. Procurador da República. E-mail: joseadercio.contato@gmail.com

\section{RESUMO}

O presente trabalho procura demonstrar que os povos tradicionais e o Brasil têm sido alvos de biopirataria de recursos ambientais naturais e de seus conhecimentos tradicionais associados, sem serem beneficiados com os recursos obtidos com a exploração de tais recursos por empresas estrangeiras. A biopirataria é uma das formas do biocolonialismo, chamado de extrativo. Discutem-se os déficits e virtudes da legislação internacional que procura combater a biopirataria, bem como o sistema jurídico brasileiro que visa preveni-la e combatê-la. Utilizou-se a metodologia teóricadocumental do tipo dedutiva, com o emprego de análises doutrinárias e legais.

Palavras-chave: biopirataria; biocolonialismo; patente; recursos naturais; conhecimentos tradicionais.

1 Trabalho financiado pelo Projeto FAPEMIG n ${ }^{\circ}$ 5236-15, resultante dos Grupos de Pesquisas (CNPq): Regulação Ambiental da Atividade Econômica Sustentável (REGA), NEGESP e CEDIS (FCT-PT). 


\section{BIOPIRACY AND TRADITIONAL KNOWLEDGE: FACES OF BIOCOLONIALISM AND HIS REGULATION}

\section{ABSTRACT}

This article tries to demonstrate that the traditional peoples and Brazil have been targets of biopiracy of natural environmental resources and their associated traditional knowledge, without being benefited with the resources obtained with the exploitation of such resources by foreign companies. Biopiracy is one of the forms of biocolonialism, called "extractive biocolonialism". It discusses the deficits and virtues of international legislation that seeks to combat biopiracy, as well as the Brazilian legal system that aims to prevent it and combat it. The theoretical-documentary methodology of the deductive type was used, based on doctrinal and legal analyzes.

Keywords: biopiracy; biocolonialism; patent; natural resources; traditional knowledge. 


\section{INTRODUÇÃO}

A biodiversidade dos países mais pobres é objeto de interesse por parte de empresas e organizações sediadas nos países ricos. Esse interesse se pode bem satisfazer por meios lícitos e contratuais, mas correntemente por intermédio de uma apropriação privada ilícita. Supostos pesquisadores extraem do patrimônio genético daqueles países amostras que são exploradas em suas sedes, convertendo-as em produtos farmacêuticos, alimentícios e cosméticos de alto valor agregado. Produtos que, protegidos pelo regime de propriedade intelectual, são vendidos em vários países por cifras expressivas. Esse cenário costuma ainda contar com a apropriação de conhecimentos seculares de povos tradicionais que servem, pelo menos, como identificadores de usos e propriedades dos bens naturais. É a forma atualizada de colonialismo e da pirataria, o biocolonialismo e a biopirataria.

O sistema jurídico internacional não tem conseguido dar respostas eficazes para prevenir e combater esse fenômeno, que agrava a assimetria social e econômica entre os países. A Convenção de Paris, a Convenção da Diversidade Biológica e a Convenção Indígenas são algumas iniciativas da espécie. A existência de normativas internacionais não prescinde de instrumentos nacionais que as tornem efetivas e aplicáveis.

Esse é o problema que se discute no presente trabalho. Para tanto, fez-se uso de uma abordagem teórica-documental do tipo dedutiva, com fontes bibliográficas e legais. Em seu primeiro capítulo, "conhecimentos tradicionais e recursos naturais", o trabalho apresenta a definição nacional e internacional dos conhecimentos tradicionais e recursos naturais, buscando associar tais definições para que seja entendido o caminhar dos conhecimentos tradicionais por meio do objeto utilizado para dar valia aos recursos naturais. A próxima parte, denominada "biopirataria", vem dispor sobre o conceito de tal termo e suas implicações, que tem, entre elas, a necessidade de atuação do poder de polícia para garantir a permanência de conhecimentos tradicionais associados face à biopirataria. $\mathrm{O}$ capítulo seguinte trata da "propriedade intelectual como garantia dos biopiratas", discutindo os mecanismos jurídicos que asseguram a proteção de patentes de produtos resultantes das atividades dos biopiratas, dando cores ao biocolonialismo.

Por sua vez, o apartado "a patente: o caso curare" apresenta a história do veneno denominado por indígenas com tal nome. A mistura que ensejou a biopirataria e o isolamento da substância ativa, alvo da patente, 
servindo de exemplo à discussão entabulada no texto. Por fim, o capítulo intitulado "a proteção jurídica contra a biopirataria" discute as iniciativas internacionais e internas de criação de instrumentos jurídicos destinados a prevenir e combater o fenômeno.

\section{CONHECIMENTOS TRADICIONAIS E RECURSOS NATURAIS}

A expressão "conhecimentos tradicionais" é empregada para definir o conjunto de crenças, rituais, costumes, saberes e práticas que são desenvolvidos e transmitidos por diversas gerações de comunidades indígenas, povos ribeirinhos, seringueiros, quilombolas e outros grupos sociais afins (INGLIS, 1993, p. 01)². A Convenção nº 169, da Organização Internacional do Trabalho (OIT) sobre Povos Indígenas e Tribais, OIT $n^{\circ}$ 169, dispõe, em seu artigo $5^{\circ}$, alínea 'a', que “os valores e práticas sociais, culturais religiosos e espirituais próprios dos povos [tradicionais] e deverão levar na devida consideração a natureza dos problemas que lhes sejam apresentados, tanto coletiva como individualmente" (BRASIL, 2004, s.p.).

No Brasil, o Decreto $\mathrm{n}^{\circ} 4.339 / 2002$ incorpora, em seu texto, princípios e diretrizes que atentam para o elemento intangível da biodiversidade, tendo em perspectiva os povos tradicionais. Esse elemento intangível engloba conhecimentos, práticas e inovações, sejam eles de quilombolas, de indígenas ou de comunidades locais diversas, traduzidos tais conhecimentos em tradicionais por efetivação.

Os conhecimentos dessas comunidades são de livre circulação, baseados que são em iniciativas antigas, quando não havia diferentes formas de compreensão sobre ambiente, além da manutenção de um sistema cultural de manejo ambiental.

A revogada Medida Provisória no 2.186/2001 definiu, em seu

\footnotetext{
2 A definição e a identificação de "comunidades" ou "povos tradicionais" ainda são objeto de debates e de um processo de construção de sentidos. No caso brasileiro, incluíam-se inicialmente apenas seringueiros e castanheiros da Amazônia. Hoje, existe quase um mosaico social de grupos sociais, que reúne de coletores de berbigão de Santa Catarina a babaçueiras do sul do Maranhão e quilombolas. Os traços que caracterizam esses grupos são: (a) baixo impacto ambiental de seus modos de vida, pelo menos, em parte da sua história; (b) interesse pela manutenção ou recuperação do controle sobre o território em que moram ou moravam e em que exploram ou exploraram; e (c) lutas de retorno às origens, por meio do reconhecimento de seus direitos e de um processo de negociação que envolve, quase sempre, a garantia do controle sobre o território e o compromisso de prestação de serviços ambientais (CUNHA; ALMEIDA, 2001, p. 184-193; SANTILLI, 2003, p. 83-97). Na diç̧ão da Lei $\mathrm{n}^{\circ}$ 13.123/2015, comunidade tradicional é um "grupo culturalmente diferenciado que se reconhece como tal, possui forma própria de organização social e ocupa e usa territórios e recursos naturais como condição para a sua reprodução cultural, social, religiosa, ancestral e econômica, utilizando conhecimentos, inovações e práticas geradas e transmitidas pela tradição" (artigo $2^{\circ}$, inciso IV) (BRASIL, 2015, s.p.).
} 
artigo $7^{\circ}$, inciso II, conhecimento tradicional. Estabeleceu, por definição, em seu texto, que "conhecimento tradicional consiste na informação ou prática individual ou coletiva de comunidade indígena ou de comunidade local, com valor real ou potencial, associada ao patrimônio genético" (BRASIL, 2001, s.p.). A atual Lei $\mathrm{n}^{\mathrm{o}}$ 13.123/2015 deu uma abrangência subjetiva maior à expressão, identificando-a com "informação ou prática de população indígena, comunidade tradicional ou agricultor tradicional sobre as propriedades ou usos diretos ou indiretos associada ao patrimônio genético" (BRASIL, 2015, s.p.).

Mediante esse reconhecimento normativo, os conhecimentos tradicionais dos povos indígenas e comunidades remanescentes de quilombos, entre outras populações tradicionais, passaram a ser fontes (re)produtoras de saberes e práticas de expressão coletiva e significação e tutela jurídicas que os confere atributividade capaz de inibir ou, pelo menos, reduzir as apropriações técnicas e culturais.

Além de todos os conhecimentos tradicionais já elencados, cabível é a referência, no presente trabalho, de saberes que envolvem, de maneira particular, o manejo dos recursos naturais. Dentre esses, a caça, a pesca e o melhoramento vegetal, além da descoberta de utilização de propriedades medicinais e alimentícias das espécies diretamente ligadas às regiões em que vivem as comunidades tradicionais.

Os conhecimentos tradicionais, como definidos, valem-se, principalmente, da natureza e dos seus recursos naturais. Qual, entretanto, o significado de "recurso natural"?

Segundo Galván, na obra intitulada Um dicionário para la educación ambiental, são recursos naturais "[...] os elementos da natureza renováveis e não renováveis utilizados pelo homem para poder satisfazer suas necessidades materiais (alimentos, vestuário, moradia, medicamentos) ou espirituais (prazer estético, recreação)". O autor ainda preleciona que recursos naturais podem ser renováveis ou não. Recursos renováveis são: "aqueles recursos naturais que têm a capacidade de perpetuar-se (por exemplo: vida animal, vegetação)" e os não renováveis são: "aqueles recursos naturais que não têm a capacidade de perpetuar-se, ao contrário, tendem a se esgotar à medida que se consomem" (GALVÁN, 2010, p. 218, tradução própria), exaurem-se.

No que tange às comunidades tradicionais sobre o respeito aos recursos naturais, a Comissão Interamericana de Direitos Humanos (CIDH), no ano de 2009, publicou o Relatório Derechos de los pueblos indígenas 
e tribales sobre sus tierras ancetrales y recursos naturales: normas y jurisprudencia del Sistema Interamericano de Derechos Humanos, e nele há a afirmativa necessária para que possam ser associados, no presente estudo, o vínculo dos conceitos "recursos naturais" e "conhecimentos tradicionais". Afirma a Comissão Interamericana de Direitos Humanos (CIDH): "a estreita relação entre os povos indígenas e tribais e seus territórios tradicionais e os recursos naturais que ali se encontram é um elemento constitutivo de sua cultura e, também, em sua forma de vida particular" (COMISSÃO INTERAMERICANA DE DIREITOS HUMANOS, 2009, p. 85 , tradução própria).

No mesmo sentido da definição da CIDH, Magalhães afirma que os conhecimentos tradicionais fazem parte das comunidades também tradicionais como objeto de propriedade intelectual e imaterial, mas de maneira sui generis. De acordo com o autor:

[...] os conhecimentos tradicionais e o direito das comunidades tradicionais [...] nova modalidade de direito de propriedade sui generis por garantir um controle com exclusividade sobre o seu uso [...] mas não durar por tempo determinado e sim indeterminado, e ter como titulares não indivíduos determinados, mas sim uma comunidade de pessoas não determinada (MAGALHÃES, 2011, p. 110).

Afirma Magalhães (2011, p. 110), ainda, que os conhecimentos tradicionais são alvo de grande interesse das indústrias farmacêuticas e alimentícias, além das indústrias de cosméticos.

Para tanto, os recursos materiais utilizados pelas comunidades tradicionais devem ser metodologicamente estudados a partir daqueles possuidores do conhecimento, os nativos ou moradores com ancestralidade definida como povo tradicional. Os conhecimentos adquiridos são, na maioria das vezes, não escritos em situações formais ou reduzidos a termo, e, por isso, não se transformam em documentos, tornando-se alvo fácil para sua perda ou apropriação por métodos como a biopirataria.

Há que ser lembrado o fato de os conhecimentos tradicionais são elementos constitutivos e inseparáveis da cultura de cada comunidade tradicional. A sua perda ou apropriação por terceiros devem ser evitadas ou, dada a dinâmica das relações humanas e sociais, pelo menos tratadas juridicamente, por motivos diferentes: um de natureza ética, com direito à cultura; outro, de cunho sociológico, pois se os conhecimentos tradicionais não forem mais reconhecidos e desaparecerem, as comunidades perdem 
identidade e cultura; um terceiro, de cariz econômico, uma vez que podem estar associados não apenas a um potencial valor de exploração, mas ao próprio sustento comunitário, à sua alimentação, saúde e qualidade de vida.

Enfim, mas não de modo exauriente, deve-se ter em conta um componente ambiental importante: Os conhecimentos tradicionais são resultado de uso sustentável da biodiversidade, o que ajuda a conservá-la.

Tampouco se pode perder de vista que tais conhecimentos podem gerar benefícios muito além da própria população tradicional, como a indução de melhorias na pesquisa científica, por meio de mais e melhores informações capazes de gerar produtos que aumentem a qualidade e mesmo o tempo de vida humana (AGRAWAL, 1995, p. 413-439). A identificação de novos paradigmas de compreensão do mundo natural e dos processos relacionais dos e com os seres humanos (COLORADO, 1988, p. 49-67; DELORIA, 1996, p. 37-44; DAVIDSON-HUNT; BERKES, 2003, s.p.) e a possibilidade de promover mudanças sociais, a partir dessa compreensão, dentro de uma perspectiva ética holística (KREMER, 1996, p. 27-36) ou, pelo menos, do desenvolvimento de adequado manejo dos recursos naturais e da realização de estudos mais apurados de impactos ambientais dos engenhos humanos (JOHANNES, 1993, p. 33-39; STEVENSON, 1996, p. 278-291; BROWN, 2003, p. 89-92; DAVIS; WAGNER, 2003, p. 463-489) $)^{3}$.

Os motivos da transcendência, no entanto, não podem autorizar o emprego de meios de apropriação cultural e a biopirataria.

\section{BIOPIRATARIA E O BIOCOLONIALISMO}

A biopirataria não é um fenômeno novo no Brasil. Embora os registros históricos sejam falhos, a história do país é marcada pela apropriação de seus recursos naturais desde a colônia. O pau-brasil talvez seja o primeiro emblema desse processo. $\mathrm{O}$ cacau, talvez, o segundo. $\mathrm{O}$ ciclo da biodiversidade do cacau teve início com a fundação da cidade de Belém e prolongou-se até a independência brasileira. Originário da Amazônia, foi levado, por volta de 1746, para a Bahia e depois para o continente africano e asiático (HOMMA, 2005, p. 48).

A borracha, talvez, o terceiro. Remonta-se, pelo menos, ao final

3 Veja-se a revisão bibliográfica em: HUNTINGTON, 2000, p. 1270-1274; FOLKE, 2004, s.p. 
do século XIX com o processo de vulcanização e utilização industrial da borracha, descoberta por Charles Goodyear em território brasileiro. No ano de 1876, a Grã-Bretanha tratou de fornecer toda a estrutura para que Henry Wickham retirasse clandestinamente do país setenta mil sementes de seringueira, de onde se extrai a matéria-prima da borracha, para levá-las às colônias britânicas na Ásia (JACKSON, 2008).

Aprática segeneralizou. Correntemente, países em desenvolvimento veem seus recursos naturais, muitas vezes, associados a conhecimentos tradicionais, serem extraídos secretamente de seu território, com vistas à sua utilização em pesquisa nos mais variados campos com o objetivo de exploração comercial futura, garantida pela propriedade intelectual. Uma garantia que impede o país de origem dos recursos auferir, pelo menos, parte dos benefícios financeiros gerados. É como afirma Rangel:

\begin{abstract}
O vivo não mais é considerado como uma dádiva da natureza, mas apenas um objeto a ser decodificado e modificado pelo homem, a fim de ser assimilado em uma atividade inventiva sob proteção das leis de propriedade intelectual. Neste exato momento, laboratórios estão ganhando milhões de dólares a partir do desenvolvimento de produtos oriundos de processos de manipulação biotecnológica [...] Assim, diante das sociedades está um território inexplorado cujos contornos vêm sendo moldados por milhares de laboratórios em universidades, agências governamentais e corporações ao redor do mundo (RANGEL, 2012, p. 92-94).
\end{abstract}

Na mesma toada, Shiva (2001, p. 101) afirma que "dos 120 princípios ativos, já isolados de plantas superiores, e utilizados na medicina moderna, 75\% foram identificados através de sistemas de conhecimentos tradicionais" e largamente utilizados na concepção de fármacos. Mas o que significa "biopirataria”? Não há uma definição propriamente jurídica do termo, cujo uso era mais corriqueiro entre ativistas e organizações não governamentais que defendiam o meio ambiente. Os autores, no entanto, tendem a concordar que a biopirataria é "o acesso a recursos genéticos de um determinado país ou aos conhecimentos tradicionais associados a tais recursos genéticos (ou a ambos), em desacordo com os princípios estabelecidos na Convenção de Diversidade biológica" (SANTILLI, 2003, p. 83; ROBINSON, 2010, p. 14)4.

4 Há quem a defina de modo mais amplo: toda forma de apropriação ilegal das formas de vida - dos 
A biopirataria tem efeitos perversos. Os simulacros de pesquisadores subtraem clandestinamente os recursos naturais e o capital genético dos países em desenvolvimento, para que sejam explorados pelas indústrias e centros de pesquisa estrangeiros, que, por seu turno, vendeos àqueles países sob a forma de novas e caras sementes, medicamentos, cosméticos e outros produtos patenteáveis. Vende-se aos países pobres a preços altos o que lhes foi ilicitamente extraído (MAGALHÃES, 2011, p. 64). É a face de um novo colonialismo, ilocucionariamente, chamado de "biocolonialismo". Há uma lógica de dominação e apropriação econômica antiga exercida com objeto e métodos não propriamente novos, mas adaptados à atual fase da economia.

O colonialismo engloba, em qualquer era, o conjunto interligado de políticas e práticas econômicas, sociais, políticas e jurídicas, que uma cultura dominante pode usar para manter e ampliar seu controle sobre outros povos e terras. No biocolonialismo, é a ciência (e mais especificamente uma a biotecnociência) que remodela todo processo. São várias as faces que o expressam. A chamada "revolução verde" é uma delas: a introdução de uma monocultura, associada a um discurso de melhoria genética e ampliação da produtividade, ameaça a diversidade genética vegetal e é acompanhada de uma divisão assimétrica de renda entre os desenvolvedores das técnicas de manipulação genética e os detentores dos espaços ocupados pela monocultura (MARDEN, 1999, p. 279-295; NEWMAN, 2000, p. 517524).

O biocolonialismo de que se trata neste texto pode ser chamado de "extrativo". Ele se utiliza da biopirataria para gerar propriedade intelectual de empresas, universidades, centros de pesquisas, consultorias e indivíduos, e, com ela, fortunas (WHITT, 1998, p. 33-67). Como no "velho" colonialismo, há uma assimetria de poderes entre o centro, detentor da técnica, e a periferia, fornecedor do recurso primário, que repete a divisão global entre norte e sul do planeta. Na forma extrativa, são os povos tradicionais, notadamente os indígenas, que, como no tempo das caravelas ou da conquista do Oeste, mais são espoliados (HARRY, 2005, p. 87-97; DI CHIRO, 2007, p. 251-283). INTERNATIONAL INSTITUTE FOR ENVIORNMENT AND DEVELOPMENT, 2006, p. 03. 


\section{A PROPRIEDADE INTELECTUAL COMO GARANTIA DOS BIOPIRATAS: A INSTRUMENTALIDADE DO BIOCOLONIALISMO}

O Direito de Propriedade Intelectual, seja em sua manifestação como direitos de patentes, seja na modalidade sui generis da propriedade intelectual associada às obtenções vegetais, não tem auxiliado na proteção dos países pobres em defesa dos seus recursos naturais e conhecimentos tradicionais associados. Em verdade, tem mais servido como um obstáculo (AOKI, 1998, p. 11-58; SARMA, 1999, p. 107-136). Interessante notar que, mesmo fruto de biopirataria, os detentores de um direito de patente ou a obtenção vegetal conseguem manter exclusividade por longos anos, graças ao regime de propriedade intelectual que atualmente vigora, tendo TRIPs um de seus principais eixos (HAMILTON, 2008, p. 26-45).

O TRIPs (sigla em inglês do Acordo sobre Aspectos dos Direitos de Propriedade Intelectual Relacionados ao Comércio), firmado na Rodada do Uruguai do Acordo Geral de Tarifas e Comércio (GATT), e gerenciado pela Organização Mundial do Comércio (OMC), surgiu como resposta à necessidade de os Estados Unidos da América (EUA), bem como União Europeia (UE) e Japão se consolidarem no cenário das patentes e afastarem ameaças vindas dos países em desenvolvimento. Tal acordo constitui-se parte integrante do sistema de acordos da OMC e foi ratificado pelo Brasil em 2001.

Ele disciplinou o sistema de patentes, estabelecendo requisitos, garantias e limitações. Há setores que não permitem o patenteamento como aqueles que envolvam métodos diagnósticos, cirúrgicos, plantas, animais e terapêuticos. Apenas micro-organismos transgênicos se tornaram patenteáveis, o que ficou claro no Brasil pela Lei 9.279/1996.

De acordo com o artigo 27.3.b do TRIPs:

3 - Os Membros também podem considerar como não patenteáveis:

b) plantas e animais, exceto micro-organismos e processos essencialmente biológicos para a produção de plantas ou animais, excetuando-se os processos não biológicos e microbiológicos. Não obstante, os Membros concederão proteção a variedades vegetais, seja por meio de patentes, seja por meio de um sistema "sui generis" eficaz, seja por uma combinação de ambos. O disposto neste subparágrafo será revisto quatro anos após a entrada em vigor do Acordo Constitutivo da OMC (BRASIL, 1994, s.p.). 
Quando os Estados em desenvolvimento assinaram o Acordo sobre a propriedade intelectual acreditavam que haveria maior escoamento de seus produtos agrícolas, pois haveria uma diminuição de barreiras internacionais para esse tipo de comercialização, o que acabou por não acontecer (AOKI, 1998, p. 20). Em contrapartida, abriram-se as portas para o fluxo internacional da sua diversidade biológica, agravada pela falta de tutela intelectual diferenciada dos conhecimentos tradicionais e de sua associação aos recursos genéticos. Deliberadamente ou não, deixava-se de prever, como exige a $\mathrm{CDB}$, a realização de contratos de repartição de benefícios na exploração de produtos que compunham a biodiversidade de um Estado. Nada que, em tese, não pudesse ser promovida por uma aplicação subsidiária.

O problema estava, na maioria dos casos, no déficit de conhecimento, por parte desses Estados, da diversidade biológica que possuíam e de seu potencial uso para fins econômicos pelas indústrias alimentares, farmacêuticas, agrícolas ou de cosmético, aplicando um conhecimento tradicional. Um déficit que se, por um lado, cegava-os das vantagens econômicas de exploração desses recursos, poderia abrir uma janela para sua consecução. É que o solicitante de uma patente deve fornecer tais informações.

Seria exatamente nesse momento que os países com grande diversidade biológica poderiam exigir a repartição de benefícios, pois estaria a patente vinculada a um contrato que dividiria as vantagens obtidas, uma vez que a matéria-prima e/ou o conhecimento tradicional associado foram retirados de terras pertencentes a um povo indígena, sendo obrigatório o compartilhamento dos benefícios auferidos. Essa proposta foi enviada para o Conselho do TRIPs por países com grande diversidade biológica, entre eles o Brasil. Poderia ser um primeiro grande passo a ser dado para fazer valer o que está disposto na CDB. Porém, não é de admirar que países como os Estados Unidos e o Japão, além da União Europeia, foram contrários à proposta, sob pretexto de que, para adoção de tal medida, teria de haver um requisito adicional para a concessão das patentes, o que não era admitido pelo Acordo TRIPs 5 .

Para os países que fizeram a requisição dessa repartição de benefícios, considerando a localização desses bens, designadamente, as

5 Para verificar crítica semelhante, pugnando pela alteração do Acordo TRIPs, no que tange as condicionantes, e ratificação do Protocolo de Nagoia pelo Congresso Nacional, como passos indispensáveis para tutelar a diversidade ambiental no Brasil, já que a regulação existente, interna e externa, são insuficientes para o intento e para distribuição igualitária dos proveitos econômicos, ver: SOARES; GOMES, 2017, p. 38-56. 
terras ancestrais de povos autóctones, sobrou uma grande insegurança jurídica e a suscetibilidade à biopirataria por não terem protegidos, de forma explícita, seus conhecimentos ${ }^{6}$. Algumas vozes são até mais críticas ao afirmarem que, no coração do tratado da OMC, habita um regime de proteção da propriedade intelectual que acaba por reconhecer a biopirataria como um "direito natural das corporações ocidentais", sob o apelo insincero de promoção do "desenvolvimento" dos países pobres (WHITT, 1998, p. 33-34; AOKI, 1998, p. 48)7.

\section{A PATENTE: O CASO "CURARE"}

Entre todos os casos de biopirataria ocorridos no Brasil, um especificamente chama a atenção pelo modo que ocorreu e se desenvolveu fora da pátria. É o caso do veneno curare, nome dado por indígenas no Estado brasileiro da Amazônia a substância usada em situações adversas e guardada até a década de 1940 em sigilo pelos pajés e curandeiros das tribos.

O curare, mistura de ervas usada nas pontas das flechas dos instrumentos de caça, denominados zarabatanas, era importante para imobilizar as presas. Proveniente dos vegetais strychnos toxifera ou chondrodendron tomentosum, é também conhecido como tubocurarina e funciona como bloqueador neuromuscular ou comumente conhecido como relaxante muscular.

Mas tais informações não foram diretamente pesquisadas da maneira como que aqui aparecem. A história do veneno guarda informações preciosas de biopirataria. Muitas etnias encontradas na Amazônia utilizam há muitos anos as propriedades do curare, mas se tem conhecimento que a primeira referência escrita sobre o curare ocorreu há séculos.

Os índios Maku, do Brasil, preparavam o veneno por meio da maceração, raspagem, secagem e cozimento dos caules e das folhas de plantas pertencentes ao gênero Strychnos spp., que depois eram colocadas nas pontas das flechas da zarabatana para imobilizar as presas. Já era a bioprospecção rudimentar ${ }^{8}$.

\footnotetext{
6 Com um olhar mais generoso sobre a proteção conferida pelo TRIPs: VISENTIN, 2012, p. 163-179.

7 A concessão pelos Estados Unidos de privilégios a organismos vivos per se, obtidos em "complicadas pesquisas genéticas", abriu espaço para que grandes corporações aumentassem o financiamento de expedições para o hemisfério sul, à caça de traços genéticos originais e/ou raros com algum valor comercial: RIFKIN, 1999, p. 52; BOFF, 2015, p. 115.
}

8 Para uma análise de uso do curare por outros povos, ver: BISSET, 1992, p. 01-26. 
A Revista Brasileira de História da Ciência, em edição de 2012, trata a história do curare no artigo "Do veneno ao antídoto: Barbosa Rodrigues e os estudos e controvérsias científicas sobre o curare". Conta a autora Sá:

O poderoso veneno dos indígenas da América do Sul gerou grande curiosidade nos primeiros exploradores que chegaram à região do vale do Amazonas e Orenoco nos séculos XVI e XVII. Desconhecido dos europeus, o veneno de ação paralisante, utilizado por algumas tribos indígenas nas pontas das flechas e dardos lançados pelas zarabatanas para a caça, era fabricado em um ritual conduzido pelo curandeiro da tribo, com a utilização de diferentes tipos de lianas e raízes em sua composição, o que levou a intensa especulação sobre que espécie seria responsável pela toxidade do veneno. Um dos primeiros exploradores que entraram em contato com o curare e descreveu os seus efeitos foi o espanhol Alonso Perez de Tolosa durante exploração do lago Maracaibo, na Venezuela, em 1548. Cristóbal Diatristán de Acuña, padre jesuíta que acompanhou Pedro Teixeira em sua exploração do Amazonas em 1639, descreveu o veneno no relato de sua viagem publicado em Madri, em 1641. Cronistas que nunca haviam viajado para o Novo Mundo também relataram o veneno mortal dos índios, como o italiano Pietro d'Anghiera que, vivendo na Espanha e utilizandose de documentos e descrições pessoais dos exploradores que estiveram nas Américas, enviava cartas para a Itália descrevendo o que ouvia. Essas cartas foram parcialmente publicadas em 1504, 1507-8, e todos os seus escritos reunidos na obra De Orbe Novo publicada em 1516, na qual descreve a técnica dos selvagens em usar arco e flechas envenenadas (SÁ, 2012, p. 15).

A mistura do veneno, depois de encontrada no território brasileiro e pesquisada por um cientista norte-americano, foi levada para pesquisa em território estrangeiro e, na década de 1970, foi patenteada, mesmo sendo fruto de biopirataria. O intervalo temporal entre a biopirataria e a patente internacional foi a garantia do esquecimento por aquele povo usurpado e deu valia aos benefícios do medicamento vendido até hoje.

A tabela abaixo demonstra a patente internacional feita pelos laboratórios das indústrias farmacêuticas Hoffmann La Roche, Omnichem S.A. e Eli Lilly and Company, respectivamente nos anos 1973, 1981 e 1984: 


\section{Tubocurarin-antigene \\ DE 2310280 A1}

$\begin{array}{ll}\text { Número da publicação } & \text { DE2310280 A1 } \\ \text { Tipo de publicação } & \text { Requerimento } \\ \text { Número do pedido } & \text { DE19732310280 } \\ \text { Data de publicação } & \mathbf{1 3} \text { set. } \mathbf{1 9 7 3} \\ \text { Data de depósito } & 1 \text { mar. } 1973 \\ \text { Data da prioridade } & \mathbf{1 0 ~ m a r . ~ 1 9 7 2} \\ \text { Também publicado como } & \text { US3809782 } \\ \text { Inventores } & \text { Sidney Spector } \\ \text { Requerente } & \text { Hoffmann La Roche } \\ \text { Exportar citação } & \text { BiBTeX, EndNote, RefMan }\end{array}$

Citada por (2), Classificações (14)

Links externos: Escritório de patentes da Alemanha (DPMA, na sigla em alemão), Espacenet

\section{CITADA POR}

\begin{tabular}{|c|c|c|c|c|}
\hline Citação & $\begin{array}{l}\text { Data de } \\
\text { depósito }\end{array}$ & $\begin{array}{c}\text { Data de } \\
\text { publicação }\end{array}$ & Requerente & Título \\
\hline EP0094844A2 * & $\begin{array}{l}18 \text { maio } \\
1983\end{array}$ & $\begin{array}{l}23 \text { nov } \\
1983 \\
21 \text { nov. } \\
1984\end{array}$ & $\begin{array}{l}\text { The Regents } \\
\text { Of The } \\
\text { University Of } \\
\text { California }\end{array}$ & Drug-carrier conjugates \\
\hline WO1987000530A1 * & $\begin{array}{l}4 \text { jul. } \\
1986\end{array}$ & 29 jan. 1987 & Huhtamaeki ou & $\begin{array}{l}\text { Protein conjugates of } \\
\text { bis-indole alkaloids, } \\
\text { bis-indole alkaloids, } \\
\text { their preparation and } \\
\text { application }\end{array}$ \\
\hline
\end{tabular}

* Citada pelo examinador 


\section{CLASSIFICAÇÕES}

$\begin{array}{ll}\begin{array}{l}\text { Classificação } \\ \text { internacional }\end{array} & \text { C07K16/16, G01N33/53, A61K39/00, G01N33/539, G01N33/531 } \\ & \text { Y10S530/806, Y10S436/815, Y10S436/823, G01N33/539, } \\ \text { Classificação cooperativa } & \text { C07K16/16, G01N33/531 } \\ \text { Classificação europeia } & \text { G01N33/531, G01N33/539, C07K16/16 }\end{array}$

Fonte: SERVIÇO DE PATENTES IFI CLAIMS, [s.d.].

Nota-se que na tabela com dados fornecidos pelo Serviço Internacional de Patentes não há nenhum requerimento de patente pelo Estado brasileiro. Seria tal omissão fundada nos acordos internacionais, que vedam o patenteamento de determinados bens, como o TRIPs? O regime de patentes e de propriedade intelectual é a chave da resposta.

O caso curare não é único. A indústria farmacêutica é um dos grandes beneficiários do regime de patentes e da biopirataria. Vários foram os recursos naturais e genéticos que, objeto de biopirataria, acabaram-se tornando medicamentos "de ponta" e caríssimos, sendo hoje vendidos nos países de origem sem qualquer retribuição ou repartição dos benefícios obtidos .

\section{A PROTEÇÃO JURÍDICA CONTRA A BIOPIRATARIA}

Embora a Convenção de Diversidade Biológica não estabeleça nenhuma normativa específica para a promoção ou para a regulamentação da prospecção de biodiversidade ${ }^{10}$, ela articula vários princípios que visam encorajar e capacitar os países em desenvolvimento a criarem seus próprios sistemas regulatórios sobre a matéria, especialmente nos contextos de acordos contratuais internacionais privados celebrados entre as partes interessadas em prospecção e os grupos locais, notadamente os tradicionais (RUBIN; FISHER, 1994, p. 31) ${ }^{11}$.

9 A Bradicina é um dos muitos exemplos. A Bradicina foi descoberta, em 1949, pelo pesquisador brasileiro Maurício Rocha e Silva, após identificar que o veneno da jararaca potencializava a produção da substância. Nos anos 1960, ela serviu de base para o desenvolvimento do Captopril, medicamento utilizado para tratamento da hipertensão e de alguns casos de insuficiência cardíaca, industrializado pelo laboratório internacional Squibb (CRUZ, 2012, s. p.).

10 A "prospecção" pode ser uma forma sofisticada (e, por vezes, com aparência de legalidade) da biopirataria, segundo: SHIVA, 2007, p. 307-313.

11 Nos termos da Convenção sobre Diversidade Biológica, os Estados não somente têm direitos soberanos sobre seus recursos naturais, mas também têm poder para determinar quem tem acesso a recursos genéticos. São três os principais objetivos da Convenção: a conservação da diversidade biológica, a uso de recursos biológicos e a partilha justa e equitativa dos benefícios resultantes 
Diferentemente do TRIPs, a Convenção tenta ajudar os países mais pobres a lidar com o desequilíbrio econômico de poder nas trocas com os países mais desenvolvidos. Impõe-se uma espécie de trade-off entre a conservação e o acesso à biodiversidade dos países sul, incluindo sua diversidade genética, e o acesso à biotecnologia e ao financiamento dos países norte. Implicitamente, ela reconhece a interdependência entre os países que controlam recursos genéticos e aqueles que possuem tecnologia e recursos para melhorar e comercializar esses recursos (SARMA, 1999, p. 121). Especialmente no tocante à salvaguarda dos direitos dos povos tradicionais, alguns documentos internacionais procuraram assegurar-lhe relativo ou pleno controle sobre os recursos naturais em seus territórios, bem como sobre seus modos de vida e usos.

O artigo 15.1 da Convenção 169 da OIT sobre Povos Indígenas e Tribais reconheceu que os direitos dos povos interessados aos recursos naturais existentes nas suas terras deveriam ser especialmente protegidos. Esses direitos abrangem o direito desses povos a participarem da utilização, administração e conservação dos recursos mencionados. $\mathrm{O}$ parágrafo seguinte estabeleceu o dever de os Estados criarem ou manterem procedimentos com vistas a consultar-lhes, a fim de se determinar se os interesses desses povos seriam prejudicados, e em que medida, antes de se empreender ou autorizar qualquer programa de prospecção ou exploração dos recursos existentes nas suas terras. Os povos interessados deverão participar, sempre que for possível, dos benefícios que essas atividades produzam, e receber indenização equitativa por qualquer dano que possam sofrer como resultado dessas atividades (BRASIL, 2004, s.p.).

A Declaração das Nações Unidas foi ainda mais enfática ao dispor no artigo 31.1 que:

\footnotetext{
Os povos indígenas têm o direito de manter, controlar, proteger e desenvolver seu patrimônio cultural, seus conhecimentos tradicionais, suas expressões culturais tradicionais e as manifestações de suas ciências, tecnologias e culturas, compreendidos os recursos humanos e genéticos, as sementes, os medicamentos, o conhecimento das propriedades da fauna e da flora, as tradições orais, as literaturas, os desenhos, os esportes e jogos tradicionais e as artes visuais e interpretativas. Também têm o direito de manter, controlar, proteger e desenvolver sua propriedade intelectual sobre o mencionado patrimônio cultural, seus conhecimentos tradicionais e suas expressões culturais tradicionais (ORGANIZAÇÃO DAS NAÇÕES UNIDAS, 2007, s.p.).
}

(SARMA, 1999, p. 120). 
A adoção de leis é a diligência primeira e necessária para que tais princípios e normas gerais sejam internalizadas. É preciso, no entanto, que haja uma atuação organizada e efetiva do poder de polícia administrativo junto às localidades onde são presentes as comunidades tradicionais, valendo-se das medidas protetivas, das sanções legais e dos princípios da autoexecutoriedade e da coercibilidade. A previsão normativa não prescinde, em casos assim, de uma intensa atividade fiscalizatória junto aos diversos profissionais e indústrias que, a pretexto de realizarem pesquisas em capo, podem estar a praticar atos de biopirataria.

Do ponto de vista legislativo, procuraram-se definir duas importantes frentes de prevenção e combate à biopirataria: a proteção contra extração de recursos naturais e a proteção dos conhecimentos tradicionais.

\subsection{A proteção contra a extração de recursos naturais no Brasil}

A quantidade expressiva de recursos naturais renováveis no território brasileiro é um convite à exploração científica para diversas finalidades, legal e ilegal. Em geral, a eles estão associados os povos tradicionais que os conhecem tão bem e deles dependem para seu processo existencial e de reprodução econômica e cultural. Nalguns casos, os usos desses recursos, senão eles próprios, pertencem à categoria do patrimônio imaterial. São mais do que elementos econômicos ou exploratórios, uma expressão espiritual daquela comunidade ou povo, o seu marco identitário.

No Brasil, a extração vegetal e mineral nas reservas extrativistas pelos próprios povos autóctones é protegida pela Lei ${ }^{\circ}$ 9.985/2000, conhecida como Lei do Sistema Nacional de Unidades de Conservação da Natureza (SNUC), que destaca, em seu artigo 18, o conceito de reserva extrativista, nos seguintes termos, in verbis:

Artigo 18 da Lei $n^{\circ}$ 9.985/2000. A Reserva Extrativista é uma área utilizada por populações extrativistas tradicionais, cuja subsistência baseia-se no extrativismo e, complementarmente, na agricultura de subsistência e na criação de animais de pequeno porte, e tem como objetivos básicos proteger os meios de vida e a cultura dessas populações, e assegurar o uso sustentável dos recursos naturais da unidade. (BRASIL, 2000, s.p.). 
De acordo com o diploma legal, a Reserva Extrativista é de domínio público, com uso concedido às populações extrativistas tradicionais, devendo os enclaves particulares ser desapropriadas, tudo de acordo com o que dispõe a lei $\left(\S 1^{\circ}\right)$. Sua gestão é atribuída a um conselho deliberativo, presidido pelo órgão responsável por sua administração e constituído por representantes de órgãos públicos, de organizações da sociedade civil e das populações tradicionais residentes na área, conforme se dispuser em regulamento e no ato de criação da unidade $\left(\S 2^{\circ}\right)$. A visitação pública é permitida, desde que compatível com os interesses locais e de acordo com o disposto no plano de manejo da área, aprovado pelo conselho $\left(\S \S 3^{\circ}\right.$ e $\left.5^{\circ}\right)$.

A pesquisa científica na área é permitida e incentivada, desde que previamente autorizada pelo órgão responsável pela administração da unidade, sujeitando-se às condições e restrições por ele estabelecidas e às normas previstas em regulamento próprio $\left(\S 4^{\circ}\right)$. Veda-se a exploração de recursos minerais e a caça amadorística ou profissional $\left(\S 6^{\circ}\right)$. A exploração comercial de recursos madeireiros é admitida, contudo, se ocorrer em bases sustentáveis e em situações especiais e complementares às demais atividades desenvolvidas na Reserva Extrativista, conforme o disposto em regulamento e no plano de manejo da unidade $\left(\S 7^{\circ}\right)$.

Além da proteção das reservas extrativistas, preocupa-se também a supracitada lei com as denominadas "reservas de desenvolvimento sustentável" ou RDS. São nelas onde as populações tratam sustentavelmente os recursos naturais, o maior alvo das indústrias farmacêuticas e alimentícias, além das cosméticas, ensejando a biopirataria. Com relação às reservas de desenvolvimento sustentável, a Lei ${ }^{\circ}$ 9.985/2000 prescreve no artigo 20, in verbis:

\begin{abstract}
Artigo 20 da Lei no 9.985/2000. A Reserva de Desenvolvimento Sustentável é uma área natural que abriga populações tradicionais, cuja existência baseia-se em sistemas sustentáveis de exploração dos recursos naturais, desenvolvidos ao longo de gerações e adaptados às condições ecológicas locais e que desempenham um papel fundamental na proteção da natureza e na manutenção da diversidade biológica. (BRASIL, 2000, s.p.).
\end{abstract}

Ela deve ter como objetivo básico preservar a natureza e, ao mesmo tempo, assegurar as condições e os meios necessários para a reprodução e a melhoria dos modos e da qualidade de vida e exploração dos recursos naturais das populações tradicionais, bem como valorizar, conservar e aperfeiçoar o 
conhecimento e as técnicas de manejo do ambiente, desenvolvido por estas populações. É a dicção quase literal do $\S 1^{\circ}$ da Lei. Também de domínio público, é gerida por um conselho deliberativo, constituído nos moldes da Reserva Extrativista ( $\S \S 2^{\circ}$ e $4^{\circ}$ ). As áreas particulares incluídas em seus limites devem ser, quando necessário, desapropriadas, de acordo com o que dispõe a lei.

As atividades desenvolvidas na RDS devem atender a algumas exigências. No caso de visitação pública, requer-se compatibilidade com os interesses locais e de acordo com o disposto no plano de manejo da área ${ }^{12}$. É permitida e incentivada a pesquisa científica voltada à conservação da natureza, à melhor relação das populações residentes com seu meio e à educação ambiental, sujeitando-se à prévia autorização do órgão responsável pela administração da unidade, às condições e restrições por ele estabelecidas e às normas previstas em regulamento. Também é admitida a exploração de componentes dos ecossistemas naturais em regime de manejo sustentável e a substituição da cobertura vegetal por espécies cultiváveis, desde que sujeitas ao zoneamento, às limitações legais e ao plano de manejo. Em qualquer caso, deve ser sempre considerado o equilíbrio dinâmico entre o tamanho da população e a conservação. O uso das áreas ocupadas pelas populações tradicionais é regulado pela própria Lei e em regulamentação específica $\left(\S \S 3^{\circ}\right.$ e $\left.5^{\circ}\right)$.

Deve-se mencionar, a esse respeito (e dentro sempre da lembrança que o tratamento aqui é indicativo e não exauriente), a Lei de Proteção dos Cultivares, $\mathrm{n}^{\circ}$ 9.456/1997, que protege as variedades de vegetais e visa regulamentar a sua patente, servindo como instrumento poderoso contra investidas dos biopiratas. Para ser obtido o registro do vegetal, são necessárias as características da distinguibilidade, da homogeneidade e da estabilidade (BRASIL, 1997, artigo 3을 inciso XII).

São, como se veem, esforços legislativos para controlar o acesso aos recursos naturais nesses espaços especiais.

\subsection{A proteção dos conhecimentos tradicionais no Brasil}

Como expressão do direito internacional da propriedade intelectual, o regime brasileiro de patentes não confere proteção ao conhecimento tradicional associado aos recursos genéticos. Sequer aceita

12 Dispõe o artigo 20, $\S 6^{\circ}$, da Lei no 9.985/2000: “O Plano de Manejo da Reserva de Desenvolvimento Sustentável definirá as zonas de proteção integral, de uso sustentável e de amortecimento e corredores ecológicos, e será aprovado pelo Conselho Deliberativo da unidade” (BRASIL, 2000, s.p.).

Veredas do Direito, Belo Horizonte, $\cdot$ v.16 $\cdot$ n.34 $\cdot$ p.91-121 $\cdot$ Janeiro/Abril de 2019 
o patenteamento de (Lei de Propriedade Industrial, $n^{\circ}$ 9.279/1996). Assim também se entende que, em virtude da exigência de originalidade da obra, os conhecimentos tradicionais não são tutelados pelo direito de autor, disciplinado pela Lei $n^{\circ}$ 9.610/1998. Tampouco o faz a Lei de Cultivares (BOFF, 2015, p. 116-117).

A legislação de proteção aos índios, designadamente o Estatuto do Índio, Lei n ${ }^{\circ} 6.001 / 1973$, protege o respeito ao patrimônio cultural das comunidades indígenas, inclusive por meio da repressão penal a ações que atentem contra a sua imagem, ou a de seus membros, e expressões de sua cultura. Essa proteção, contudo, não tem sido capaz de impedir a apropriação dos direitos imateriais indígenas, de seus mitos, seus cantos, seus ritos e saberes (BOFF, 2015, p. 117).

O reconhecimento constitucional dos direitos indígenas sobre seus bens imateriais (artigo 231) carecia de um regime legal mais eficaz. O primeiro grande impulso foi dado por meio da Medida Provisória ${ }^{\circ}$ 2.816/2001. Ela tratou de definir o que seriam conhecimentos tradicionais associados. No entanto, ela não deu conta de tutelar o direito aos conhecimentos tradicionais e recursos naturais de forma eficaz, tendo sido revogada pela Lei $n^{0} 13.123 / 2015$, que buscou aprimorá-la ${ }^{13}$. De acordo com a nova lei, considera-se acesso ao patrimônio genético a pesquisa ou desenvolvimento tecnológico realizado sobre amostra de patrimônio genético. Acesso ao conhecimento tradicional associado, a pesquisa ou desenvolvimento tecnológico realizado sobre conhecimento tradicional associado, que viabilize o acesso ao patrimônio genético.

O conhecimento tradicional associado, como se viu, é a informação ou a prática dos povos tradicionais sobre as propriedades ou usos, diretos ou indiretos, associada ao patrimônio genético. Ele é divido em "conhecimento tradicional de origem não identificável” e "identificável”. No primeiro, não há a possibilidade de vinculação da sua origem a um povo indígena, a uma comunidade tradicional ou a um agricultor tradicional. É um conhecimento difuso. No segundo, é possível a sua atribuição a um determinado grupo. Essa distinção tem reflexo nas exigências e consequências de acesso. Em se tratando de conhecimento identificável, deve-se obter o consentimento prévio informado da comunidade em questão, o que não é exigível no primeiro caso (artigo $9^{\circ}$, caput e $\S 2^{\circ}$ ). Se a retribuição pelo acesso ao

13 A citada lei não está isenta de críticas, pois busca estabelecer como órgão unicamente competente para manutenção e preservação dos recursos naturais a União, em detrimento da atribuição comum que deve ser dada a todos os entes federados quando da preservação do meio ambiente. Nesse sentido, ver: GOMES; VASCONCELOS, 2016, p. 362. 
conhecimento identificável é feita à comunidade específica; no não identificável, como o chá de quebra-pedra, o valor vai para um fundo comum (artigos 23 e 24).

Certo é que se procurou estabelecer a retributividade ou repartição dos benefícios gerados pela exploração econômica decorrente tanto de acesso ao patrimônio genético, quanto ao conhecimento tradicional associado. É como determina o artigo 17 da Lei:

\begin{abstract}
Artigo 17 da Lei $n^{\circ}$ 13.123/2015. Os benefícios resultantes da exploração econômica de produto acabado ou de material reprodutivo oriundo de acesso ao patrimônio genético de espécies encontradas em condições in situ ou ao conhecimento tradicional associado, ainda que produzido fora do país, serão repartidos, de forma justa e equitativa, sendo que no caso do produto acabado o componente do patrimônio genético ou do conhecimento tradicional associado deve ser um dos elementos principais de agregação de valor, em conformidade ao que estabelece esta Lei (BRASIL, 2015, s.p.).
\end{abstract}

Cuida-se, como se nota, de um empenho legislativo no sentido de retribuir aos povos tradicionais uma parcela, ao menos, dos benefícios gerados pela exploração econômica dos recursos naturais e do conhecimento tradicional associado.

\title{
5.3 A quebra legal de patente: uma possibilidade de resistência ao biocolonialismo? O caso curare em questão
}

Os sistemas jurídicos nacionais têm procurado ajustar suas normas de proteção à biodiversidade e aos conhecimentos tradicionais, também por meio da quebra de patentes. Essa é uma previsão que tem limitações importantes, derivadas tanto, e principalmente, dos conflitos contra interesses poderosos das grandes corporações e governos de países ricos ${ }^{14}$; quanto, e consequente a isso, pelo número ainda reduzido de possibilidades de sua aplicação. O campo dos fármacos é uma dessas possibilidades, com a introdução dos chamados "medicamentos genéricos"15. Não é à toa que teve início exatamente por iniciativa do governo dos Estados Unidos na

14 A política de medicamentos genéricos do Brasil encontrou forte resistência externa, notadamente dos Estados Unidos. Ver: OLIVEIRA; MORENO, 2007, p. 189-220.

$15 \mathrm{Na}$ defesa da aplicação da Convenção de Diversidade Biológica (CDB) a favor da quebra de patentes: SANTOS, 2011, p. 63-98.

Veredas do Direito, Belo Horizonte, $\cdot$ v.16 $\cdot$ n.34 · p.91-121 $\cdot$ Janeiro/Abril de 2019 
década de $1960^{16}$. Em 1984, por meio da Drug Price Competition and Patent Term Restoration Act, foram estabelecidos os critérios para sua produção e comercialização que se tornaram internacionalmente aceitos, baseados na comprovação da qualidade de seus processos de fabricação e da bioequivalência entre o genérico e o medicamento de referência (ALENCAR; LEITÃO; LOIOLA, 2016, p. 47) ${ }^{17}$.

No Brasil, a Lei $n^{0} 9.787 / 1999$ disciplina a matéria ${ }^{18}$. Na linguagem do seu artigo $3^{\circ}$, inciso XXI, um medicamento genérico é um fármaco "similar a um produto de referência ou inovador, que se pretende ser com este intercambiável, geralmente produzido após a expiração ou renúncia da proteção patentária ou de outros direitos de exclusividade, comprovada a sua eficácia, segurança e qualidade, e designado pela DCB ou, na sua ausência, pela DCI". O produto de referência é aquele que fez uso inovador de substância ou princípio ativo com registro no órgão federal responsável pela vigilância sanitária e comercializado no país, cuja eficácia, segurança e qualidade foram comprovadas cientificamente junto ao órgão federal competente, por ocasião do registro (XXII). Por seu turno, um produto farmacêutico intercambiável é o equivalente terapêutico de um medicamento de referência, comprovados, essencialmente, os mesmos efeitos de eficácia e segurança (XXIII) (BRASIL, 1999, s.p.).

Esses dispositivos podem ser empregados como instrumento de minimização dos desvios causados pela biopirataria. Tome-se o exemplo do veneno curare que, como se disse, foi objeto de biopirataria e é a base do Tubocurarine Antigens and Antibodies. O medicamento estrangeiro teria o caráter de intercambialidade e equivalência terapêutica com produto também desenvolvido no Brasil desde, pelo menos, 1873 (SÁ, 2012, p. 15). Em sendo assim, seria aplicável o artigo $3^{\circ}$, inciso XXIII, da Lei ${ }^{\circ}$ 9.787/1999, numa leitura conforme aos artigos $6^{\circ}$ e 196 da Constituição da República de 1988, que asseguram a todos o direito à saúde.

Claro está que se trata de uma solução polêmica e circunscrita

$16 \mathrm{Na}$ verdade, a denominada 'quebra' de patente ocorre em situações muito específicas, previstas em lei e fundadas na Convenção de Paris e no TRIPs. Ver: BARCELLOS, 2004, p. 23.

17 A Agência de Saúde e Agricultura daquele país, a (FDA) criou um processo simplificado de registro para medicamentos genéricos (ANDA - Abbreviated New Drug Application). "A partir do Hatch-Waxman, a bioequivalência passou a ser cientificamente aceita para comprovação da eficácia e segurança dos medicamentos genéricos. Assim, a indústria de medicamentos ganhou competitividade, disponibilizando genéricos com qualidade comprovada pelo FDA e beneficiando a população pela oferta de medicamentos eficazes e seguros em larga escala" (ALENCAR; LEITÃO; LOIOLA, 2016, p. 47).

18 Sobre a história dos fármacos e genéricos no Brasil, ver, dentre outros: JUCHEM; BRAGA; CHAVES, 2006, s.p. 
ao contexto de comprovada biopirataria e antecedência fática de desenvolvimento local do produto patenteado lá fora. Pode ser, todavia, uma alternativa a ser utilizada contra a biopirataria e ao biocolonialismo. Certo, envolta em complexidades, mas uma a mais.

\section{CONSIDERAÇÕES FINAIS}

A biopirataria se mostra como um problema recorrente no atual cenário brasileiro, especialmente porque o Brasil, como já demonstrado ao longo do presente trabalho, é um país detentor de diversos recursos naturais e de conhecimentos tradicionais que aguçam o interesse de outros Estados soberanos.

Buscou-se analisar, com o presente artigo, o fenômeno da biopirataria no cenário brasileiro e mundial, estabelecendo quais são as diretrizes a serem seguidas, a fim de amenizar o efeito de tão degradante fenômeno.

Inicialmente, procurou-se estabelecer o conceito de conhecimentos tradicionais e em qual medida eles foram e são afetados pela biopirataria. Constatou-se que os indígenas, bem como outras populações tradicionais, são alcançados pela biopirataria, justamente porque veem seus recursos naturais e conhecimentos a eles associados serem explorados, sem participarem dos benefícios de tal exploração.

Em um segundo momento, buscou-se determinar o conceito de biopirataria e definir em que medida se dá a exploração dos recursos naturais. Constatou-se que os países que detém maior biodiversidade constituem alvo fácil do fenômeno mencionado, vez que apresentam uma matriz diversificada e mais propícia a descobertas no âmbito da ciência.

O sistema de proteção internacional da propriedade intelectual tem servido de estímulo à biopirataria e de barreira às reivindicações dos povos tradicionais de participação nos benefícios gerados pela exploração de seus recursos naturais e conhecimentos tradicionais associados. O Acordo TRIPs tem sido um instrumento que reproduz esse quadro de dificuldade. O caso do curare serve de exemplo a essa situação de desproteção. Mesmo depois de constatada a biopirataria, essa mistura do veneno foi patenteada no estrangeiro.

No plano internacional, a Convenção de Paris e a Convenção sobre a Diversidade Biológica previram a necessidade de proteção dos recursos naturais e dos conhecimentos tradicionais associados. Entretanto, somente 
a Convenção Indígena reconheceu aos povos tradicionais, notadamente os indígenas, além da propriedade e posse do território que tradicionalmente ocupam, o poder de controlar o acesso aos conhecimentos tradicionais, bem como o direito de uma proteção jurídica e judicial efetiva. É claro que, como as outras duas Convenções, sua eficácia depende dos mecanismos de internacionalização de seus comandos e dos instrumentos políticos e processuais de sua execução e aplicação.

O sistema jurídico brasileiro procurou internalizar os princípios daquelas Convenções. A Lei no 9.985/2000 previu, por exemplo, um regime especial de proteção e de restrição à extração de produtos naturais em áreas de especial relevância ambiental como as reservas extrativistas e as reservas de desenvolvimento sustentável. Assim também a Lei $\mathrm{n}^{\circ}$ 13.123/2015 estabeleceu a disciplina sobre o acesso ao patrimônio genético, a proteção e o acesso ao conhecimento tradicional associado e sobre a repartição de benefícios para conservação e uso sustentável da biodiversidade.

Há, por fim, de se mencionar a Lei $n^{\circ} 9.787 / 1999$, que trata do uso de medicamentos genéricos e similares, como uma alternativa a mais, embora sabidamente limitada, para tentar, por meio da quebra de patente, em situações como a da apropriação farmacêutica do curare, reduzir os impactos negativos da biopirataria e do biocolonialismo.

\section{REFERÊNCIAS}

AGRAWAL, Arun. Dismantling the divide between indigenous and scientific knowledge. Development and Change, v. 26, p. 413-439, 1995.

ALENCAR, A. R.; LEITÃO, J. M. R.; LOIOLA, P. J. Adesão ao tratamento com medicamento genéricos no Brasil: uma revisão integrativa. Revista Saúde em Foco, Teresina, v. 3, no 1, p. 46-65, jan./jun. 2016. Disponível em: <http://www4.fsanet.com.br/revista/index.php/saudeemfoco/article/ view/905>. Acesso em: 19 abr. 2018.

AOKI, Keith. Neocolonialism, anticommons property, and biopiracy in the (not-so-brave) new world order of international intellectual property protection. Indiana Journal of Global Legal Studies, v. 6, n 11, p. 11-58, 1998.

BARCELLOS, Milton Lucídio L. O sistema internacional de patentes. São Paulo: IOB Thomson, 2004. 
BISSET, N. G. War and hunting poisons of the new world. Part 1: notes on the early history of curare. J Ethnopharmacol, v. 36, p. 1-26, fev. 1992. Disponível em: <https:/www.ncbi.nlm.nih.gov/ pubmed/1501489>. Acesso em: 22 abr. 2018.

BOFF, Salete Oro. Acesso aos conhecimentos tradicionais: repartição de benefícios pelo 'novo' marco regulatório. Revista Direito Ambiental e Sociedade, Caxias do Sul, v. 5, no 2, p. 110-127, 2015. Disponível em: $<$ http://ucs.br/etc/revistas/index.php/direitoambiental/article/view/3951>. Acesso em: 22 abr. 2018.

BRASIL. Constituição da República Federativa do Brasil de 1988. Diário Oficial da União, Brasília, out. 1988. Disponível em: $<$ http:// www.planalto.gov.br/ccivil_03/constituicao/constituicao.htm>. Acesso em: 07 jan. 2018.

BRASIL. Decreto n ${ }^{\circ} 1.355$, de 30 dez. 1994. Promulgo a Ata Final que Incorpora os Resultados da Rodada Uruguai de Negociações Comerciais Multilaterais do GATT. Diário Oficial da União, Brasília, 31 dez. 1994. Disponível em: <http:/www.planalto.gov.br/ ccivil_03/decreto/antigos/d1355.htm>. Acesso em: 14 fev. 2018.

BRASIL. Decreto n ${ }^{0}$ 5.051, de 19 abr. 2004. Convenção 169 da OIT. Promulga a Convenção $n^{0} 169$ da Organização Internacional do Trabalho - OIT sobre Povos Indígenas e Tribais. Diário Oficial da União, Brasília, 20 abr. 2004. Disponível em: <http://www.planalto.gov.br/ccivil_03/_ Ato2004-2006/2004/Decreto/D5051.htm>. Acesso em: 19 abr. 2018.

BRASIL. Lei no 9.456/1997, de 25 abr. 1997. Institui a Lei de Proteção de Cultivares e dá outras providências. Diário Oficial da União, Brasília, 25 set. 1997. Disponível em: <http://www.planalto.gov.br/ccivil_03/Leis/ L9456.htm>. Acesso em 20 abr. 2018.

BRASIL. Lei $\mathrm{n}^{\circ}$ 9.787, de 10 fev. 1999. Altera a Lei $\mathrm{n}^{\circ}$ 6.360, de 23 de setembro de 1976, que dispõe sobre a vigilância sanitária, estabelece o medicamento genérico, dispõe sobre a utilização de nomes genéricos em produtos farmacêuticos e dá outras providências. Diário Oficial da União, Brasília, 11 fev. 1999. Disponível em: <http://www.planalto.gov. br/ccivil_03/Leis/L9787.htm>. Acesso em: 07 jan. 2018. 
BRASIL. Lei $n^{\circ}$ 9.985, 18 jul. 2000. Regulamenta o art. 225, § 1丷, incisos I, II, III e VII da Constituição Federal, institui o Sistema Nacional de Unidades de Conservação da Natureza e dá outras providências. Diário Oficial da União, Brasília, 19 jul. 2000. Disponível em: <http://www. planalto.gov.br/CCIVIL_03/leis/L9985.htm>. Acesso em: 07 jan. 2018.

BRASIL. Lei $\mathrm{n}^{\circ}$ 13.123/2015, de 20 maio 2015. Regulamenta o inciso II do $\S 1^{\circ}$ e o $\S 4^{\circ}$ do art. 225 da Constituição Federal, o Artigo 1, a alínea $j$ do

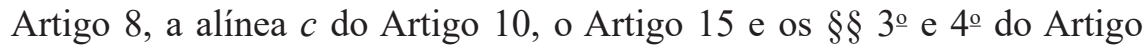
16 da Convenção sobre Diversidade Biológica, promulgada pelo Decreto no 2.519, de 16 de março de 1998; dispõe sobre o acesso ao patrimônio genético, sobre a proteção e o acesso ao conhecimento tradicional associado e sobre a repartição de benefícios para conservação e uso sustentável da biodiversidade; revoga a Medida Provisória no 2.186-16, de 23 de agosto de 2001; e dá outras providências. Diário Oficial da União, Brasília, 20 maio 2015. Disponível em: <http://www.planalto.gov.br/ccivil_03/_ato20152018/2015/lei/113123.htm>. Acesso em: 14 fev. 2018.

BROWN, Katrina. Three challenges for a real people-centred conservation. Global Ecology and Biogeography, v. 12, p. 89-92, 2003.

CASTILHO, Ela Wiecko Volkmer de. Diversidade biológica: questões controvertidas na proteção do conhecimento tradicional. Revista Meio Ambiente - Série Grandes Eventos, Brasília, p. 1-5, 2003. Disponível em: $\quad<$ http://escola.mpu.mp.br/linha-editorial/outras-publicacoes/seriegrandes-eventos-meio-ambiente/Ela_Wiecko_Diversidade_biologica. pdf $>$. Acesso em: 10 jan. 2018.

COLORADO, Pam. Bridging native and western science. Convergence, v. XXI, p. 49-67, 1988.

COMISSÃO INTERAMERICANA DE DIREITOS HUMANOS. Informe anual de la Comisión Interamericana de Derechos Humanos, 2009. Disponível em: <https://cidh.oas.org/pdf\%20files/ANUAL\%202009\%20 ESP.pdf $>$. Acesso em: 12 fev. 2018.

CRUZ, Fernanda. USP pesquisa molécula capaz de reverter a morte de células cerebrais. Radiobrás, 2012. Disponível em: <http://www.ebc.com. br/2012/10/usp-pesquisa-molecula-capaz-de-reverter-a-morte-de-celulascerebrais $>$. Acesso em: 10 jan. 2018. 
CUNHA, Manuela Carneiro da; ALMEIDA, Mauro W. Barbosa de. Populações tradicionais e conservação ambiental. In: CAPOBIANCO, João Paulo Ribeiro; et al. (Orgs.). Biodiversidade na Amazônia Brasileira: avaliação e ações prioritárias para a conservação, uso sustentável e repartição de benefícios. São Paulo: Estação Liberdade; ISA, 2001. p. 184193.

CURARE: o silencioso veneno da Amazônia. Revista de Atualidade Indígena, Brasília, v. 1, nº 6, p. 57-63, 1977.

DAVIDSON-HUNT, Iain; BERKES, Fikret. Learning as you journey: anishinaabe perception of social-ecological environments and adaptive learning. Conservation Ecology, v. 8, $\mathrm{n}^{\mathrm{o}}$ 1, s.p., 2003. Disponível em: $<$ https://www.ecologyandsociety.org/vol8/iss1/art5/>. Acesso em: 21 abr. 2018.

DAVIS, Anthony; WAGNER, John R. Who knows? On the importance of identifying experts when researching local ecological knowledge. Human Ecology, v. 31, p. 463-489, 2003.

DELORIA, Vine. If you think about it, you will see that it is true. ReVision, v. 18, p. 37-44, 1996.

DI CHIRO, Giovanna. Indigenous peoples and biocolonialism: defining the "science of environmental justice" in the century of the gene. In: SANDLER, Ronald; PEZZULLO, Phaedra C.(Eds.). Environmental justice and environmentalism: the social justice challenge to the environmental movement. Cambridge, MA: MIT Press, 2007. p. 251-283.

FOLKE, Carl. Traditional knowledge in social-ecological systems. Ecology and Society, v. 9, n 3, s.p., 2004. Disponível em: <https://dlc.dlib.indiana. edu/dlc/bitstream/handle/10535/3323/http__ www.ecologyandsociety. org_vo19_iss3_art7_.pdf?sequence=1>. Acesso em: 20 abr. 2018.

GALVÁN, Rafael Barla. Un dicionario para la educación ambiental. Argentina: El Castellano, 2010.

GOMES, Magno Federici; VASCONCELOS, Carlos Frederico Saraiva de. Das atribuições administrativas na gestão e supervisão do patrimônio genético brasileiro. Revista Eletrônica do curso de Direito da UFSM, v. 11, $\mathrm{n}^{\circ}$ 1, p. 348-364, jan./abr. 2016. Disponível em: <https://periodicos.ufsm. br/revistadireito/article/view/21490/pdf_1>. Acesso em: 12 jan. 2018. 
HAMILTON, Chris. Intellectual property rights, the bioeconomy and the challenge of biopiracy. Genomics, Society and Policy, v. 4, nº 3, p. 26-45, 2008 .

HARRY, Debra. Acts of self-determination and self-defense: indigenous peoples' responses to biocolonialism. In: KRIMSKY, S.; SHORETT, P. (Eds.). Rights and liberties in the biotech age. Lanham: Roman and Littlefield, 2005. p. 87-97.

HOMMA, Alfredo K. O. Biopirataria na Amazônia: como reduzir os riscos. Amazônia: Ciência \& Desenvolvimento, v. 1, nº 1, p. 47-60, 2005.

HUNTINGTON, Henry P. Using traditional ecological knowledge in science: methods and applications. Ecological applications, v. 10, $\mathrm{n}^{\circ} 5$, p. 1270-1274, 2000.

INGLIS, Julian. Traditional ecological knowledge concepts and cases. Ottawa: International Program on Traditional Ecological Knowledge,1993.

INTERNATIONAL INSTITUTE FOR ENVIORNMENT AND DEVELOPMENT. Protecting indigenous knowledge against biopiracy in the Andes. London: IIED, 2006.

JACKSON, Joe. The thief at the end of the world - rubber, empire and the obsessions of Henry Wickham. London: Duckworth, 2008.

JOHANNES, Robert E. Integrating traditional ecological knowledge and management with environmental impact assessment. Traditional ecological knowledge: concepts and cases, v. 1, p. 33-39, 1993.

JUCHEM, Dionise M.; BRAGA, Dione da Silva; CHAVES, Aurélio Ricardo Troncoso. Medicamentos genéricos enfocando o seu mark share e a sua aceitabilidade. In: Anais do III CONVIBRA, de 24 a 26 de novembro de 2006. s.p. Disponível em: <http://www.convibra.org/2006/artigos/37_ pdf.pdf $>$. Acesso em: 20 abr. 2018.

KREMER, J. Evolving into what, and for whose purposes? Reading bateson. ReVision, v. 18, p. 27-36, 1996.

MAGALHÃES, Vladimir Garcia. Propriedade intelectual: biotecnologia e biodiversidade. São Paulo: Fiuza, 2011. 
MARDEN, Emily. The neem tree patent: international conflict over the commodification of life. Boston College Int'l \& Comparative Law Review, v. 22, p. 279-295, 1999.

NEWMAN, Stuart A. The role of genetic reductionism in biocolonialism. Peace Review, v. 12, no 4, p. 517-524, 2000.

OLIVEIRA, Marcelo Fernandes de; MORENO, Fernanda Venceslau. Negociações comerciais internacionais e democracia: o contencioso Brasil x EUA das patentes farmacêuticas na OMC. Dados, Rio de Janeiro, v. 50, no 1, p. 189-220, 2007. Disponível em: <http://www.scielo.br/scielo. php?script $=$ sci_arttext\&pid=S0011-52582007000100007\&lng=en\&nrm= iso >. Acesso em: 22 abr. 2018.

ORGANIZAÇÃO DAS NAÇÕES UNIDAS. Declaração das Nações Unidas sobre os Direitos dos Povos Indígenas. $107^{\text {a }}$ Sessão Plenária, de 13 de setembro de 2007. Disponível em: <http://www.un.org/esa/socdev/ unpfii/documents/DRIPS_pt.pdf>. Acesso em 20 abr. 2018.

RANGEL, Helano Márcio Vieira. A proteção da propriedade intelectual e a biopirataria do patrimônio genético amazônico à luz de diplomas internacionais. Revista Veredas do Direito, Belo Horizonte, v. 9, $\mathrm{n}^{\mathrm{o}} 18$, p. 89-115, jul./dez. 2012. Disponível em: $<$ http://www.domhelder.edu.br/ revista/index.php/veredas/article/view/247>. Acesso em: 19 abr. 2018.

RIFKIN, Jeremy. O século da biotecnologia. Tradução de Arão Sapiro. São Paulo: Makron Books, 1999.

ROBINSON, Daniel F. Confronting biopiracy: challenges, cases and international debates. London: Routledge, 2010.

RUBIN, Steven M.; FISH, Stanwood W. Biodiversity prospecting: using innovative contractual provisions to foster ethnobiological knowledge, technology, and conservation. Colorado Journal of International Environmental Law and Policy, v. 5, n 1, p. 23-58, 1994.

SÁ, Magali Romero. Do veneno ao antídoto: Barbosa Rodrigues e os estudos e controvérsias científicas sobre o curare. Revista Brasileira de História da Ciência, Rio de Janeiro, v. 5, suplemento, p. 12-21, 2012. Disponível em: <http://www.jbrj.gov.br/sites/all/themes/corporateclean/ content/publicacoes/SBHC\%202012_suplemento.pdf $>$. Acesso em: 12 jan. 2018. 
SANTILLI, Juliana. Biodiversidade e conhecimentos tradicionais associados: novos avanços e impasses na criação de regimes legais de proteção. Revista de Direito Ambiental, São Paulo, v. 8, n 29, p. 83-97, 2003.

SANTOS, Diogo de Almeida Viana. A suspensão da validade de patentes como instrumento de garantia de repartição de benefícios para conhecimento tradicional e implementação da CBD. Revista Veredas do Direito, Belo Horizonte, v. 8, nº 16, p. 63-98, jul./dez. 2011. Disponível em: <http://www.domhelder.edu.br/revista/index.php/veredas/article/ view/216>. Acesso em: 22 abr. 2018.

SARMA, Lakshmi. Biopiracy: Twentieth century imperialism in the form of international agreements. Temple Int'l \& Comparative Law Journal, v. 13, no 1, p. 107-136, 1999.

SERVIÇO DE PATENTES IFI CLAIMS. Patentes: tubocurarin-antigene. Google, [s.d.]. Disponível em: <https:/encrypted.google.com/patents/ DE2310280A1?cl=nl>. Acesso em: 19 abr. 2018.

SHIVA, Vandana. Biopirataria: a pilhagem da natureza e do conhecimento. Tradução de Laura Cardellini Barbosa de Oliveira. Petrópolis: Vozes, 2001.

SHIVA, Vandana. Bioprospecting as sophisticated biopiracy. Signs: Journal of Women in Culture and Society, v. 32, nº 2, p. 307-313, 2007.

SOARES, Igor Jotha; GOMES, Magno Federici. Propriedade intelectual, biodiversidade e biopirataria: a preservação do patrimônio genético ambiental brasileiro requer regulação eficaz. Revista de Biodireito e Direitos dos Animais, Maranhão, v. 3, n. 2, p. 38-56, jul./dez. 2017. Disponível em: $\quad<$ http://dx.doi.org/10.26668/IndexLawJournals/2525-9695/2017. v3i2.2245>. Acesso em: 19 abr. 2018.

STEVENSON, Marc G. Indigenous knowledge in environmental assessment. Arctic, v. 49, p. 278-291, 1996.

UNCTAD. United Nations Conference on Trade and Development. Systems and national experiences for protecting traditional knowledge, innovations and practices. UNCTAD, Genebra, 2000. Disponível em: $<$ http://www.unctad.org/>. Acesso em: 23 fev. 2018. 
VISENTIN, Maria Alice Dias R. Acesso a recursos genéticos, repartição de benefícios e propriedade intelectual: a conservação da biodiversidade e os direitos de patentes. Revista Veredas do Direito, Belo Horizonte, v. 9, $\mathrm{n}^{\circ}$ 17, p. 163-179, jan./jul. 2012. Disponível em: <http://www.domhelder.edu. br/revista/index.php/veredas/article/view/229>. Acesso em: 22 abr. 2018.

WHITT, Laurie A. Biocolonialism and the commodification of knowledge. Science as Culture, v. 7, n. 1, p. 33-67, 1998.

Artigo recebido em: 23/07/2018.

Artigo aceito em: 22/02/2019.

\section{Como citar este artigo (ABNT):}

GOMES, M. F.; SAMPAIO, J. A. L. Biopirataria e conhecimentos tradicionais: as faces do biocolonialismo e sua regulação. Veredas do Direito, Belo Horizonte, v. 16, n. 34, p. 91-121, jan./abr. 2019. Disponível em: <http:/www.domhelder.edu.br/revista/index.php/ veredas/article/view/1274>. Acesso em: dia mês. ano. 